Article

\title{
Boron Nitride Nanosheets/PNIPAM Hydrogels with Improved Thermo-Responsive Performance
}

\author{
Shishan Xue ${ }^{1}$, Yuanpeng $\mathrm{Wu}^{1,2, *}$, Jiemin Wang ${ }^{3}$, Meiling Guo ${ }^{1}$, Dan Liu ${ }^{3, *}$ and Weiwei Lei ${ }^{3, *}$ \\ 1 School of Material Science and Engineering, Southwest Petroleum University, Chengdu 610500, China; \\ 201711000008@stu.swpu.edu.cn (S.X.); 201621000011@stu.swpu.edu.cn (M.G.) \\ 2 State Key Laboratory of Oil and Gas Reservoir Geology and Exploitation, Southwest Petroleum University, \\ Chengdu 610500, China \\ 3 Institute for Frontier Materials, Deakin University, Locked Bag 2000, Geelong, VIC 3220, Australia; \\ jiemin@deakin.edu.au \\ * Correspondence: ypwu@swpu.edu.com (Y.W.); dan.liu@deakin.edu.au (D.L.); \\ weiwei.lei@deakin.edu.au (W.L.); Tel.: +86-028-8303-7404 (Y.W.)
}

Received: 2 June 2018; Accepted: 20 June 2018; Published: 24 June 2018

\begin{abstract}
Thermo-responsive hydrogel is an important smart material. However, its slow thermal response rate limits the scope of its applications. Boron nitride nanosheet-reinforced thermos-responsive hydrogels, which can be controlled by heating, were fabricated by in situ polymerization of $\mathrm{N}$-isopropylacrylamide in the presence of boron nitride nanosheets. The hydrogels exhibit excellent thermo-responsiveness and much enhanced thermal response rate than that pure poly( $N$-isopropylacrylamide) hydrogels. Interestingly, the hydrogels can be driven to move in aqueous solution by heating. Importantly, the composite hydrogel is hydrophilic at a temperature below lower critical solution temperature (LCST), while it is hydrophobic at a temperature above LCST. Therefore, it can be used for quick absorption and release of dyes and oils from water. All these properties demonstrate the potential of hydrogel composites for water purification and treatment.
\end{abstract}

Keywords: thermal-responsive; hydrogel; boron nitride nanosheets; poly( $N$-isopropylacrylamide)

\section{Introduction}

Heat transport is important in biomedical and biotechnological processes [1]. Extreme heating such as ablation can be used to destroy cancers and tumors, while cooling of organs destined for transplantation prevents cell and tissue damage [2]. So heat conduction rate plays a key role in the process of treatment of bad tissues [3]. Hydrogel is a three-dimensional cross-linked polymeric network [4] and can swell in aqueous medium [5]. Smart hydrogels, also called "the stimulus responsive hydrogels", have attracted much academic and industrial attention due to their excellent external stimuli responsive properties, such as temperature, $\mathrm{pH}$, photons, or magnetic responsiveness [6].

Among them, the environmentally thermo-responsive poly( $N$-isopropylacrylamide) (PNIPAM) hydrogel has the most potential since it is reversible from hydrophilicity to hydrophobicity when the temperature reaches the lower critical solution temperature (LCST) of around $32{ }^{\circ} \mathrm{C}$ [7-10]. Such smart properties endow it with diverse applications in biomedicine [11,12], drug delivery [13,14], hydrogen storage $[15,16]$ and field emitting $[17,18]$. However, the slow thermal responsive rate upon heating/cooling across the LCST of PNIPAM severely limits their applications. To improve the response rate of PNIPAM-based thermo-responsive hydrogel, different strategies have been developed, such as modifying the structures of hydrogels by incorporating nano-fillers [10-12]. Recent work reveals that the combination of two-dimensional (2D) nanomaterials, such as grapheme and $\mathrm{MoS}_{2}$, 
with PNIPAM hydrogels results in an impressive thermo-response rate [19-22]. Therefore, searching for new 2D candidate compatibility with PNIPAM is still an urgent task.

Boron nitride nanosheet (BNNS), also called "white graphene" [23], possesses excellent thermal conductivity $\left(\sim 6000 \mathrm{~W} \cdot \mathrm{m}^{-1} \cdot \mathrm{K}^{-1}\right)$ [24], significant chemical inertness [25], uniquely mechanical properties [26], high resistant to oxidation (stable up to $840{ }^{\circ} \mathrm{C}$ in air), low dielectric constant [27], and exceptional electrical insulativity [28]. Such outstanding properties make it highly promising in a wide range of applications such as field nano-emitters, hydrogen storage, organic pollutant adsorption and clean-up of oil spillage [14]. However, to the best of our knowledge, only a few investigations have been devoted to preparing smart nanocomposites hydrogels with BNNS for improving the thermal response. Most recently, Xiao [25] reported that exfoliated hydroxyl functionalized-BNNS (BNNS-OH) which have been incorporated into PNIPAM hydrogels for enhancing thermal response. However, the low concentration $(0.06 \mathrm{mg} / \mathrm{mL})$ of BNNS-OH in ethanol by a steam treatment method [25] may present a severe limitation for the aqueous suspensions preferred in many practical applications.

In this work, the as-produced few-layer amino functionalized-BNNS $\left(\mathrm{BNNS}-\mathrm{NH}_{2}\right)$ with high dispersibility in water, yielding stable colloidal solutions with concentrations up to $0.20 \mathrm{mg} / \mathrm{mL}$ are introduced into the thermally responsive hydrogels, PNIPAM (Scheme 1) [14]. The composite hydrogels exhibit more sensitive property to temperature change. Moreover, the smart composite hydrogel shows extraordinary large responsive swelling ratio and rapid response rate. Importantly, the resulting smart hydrogel demonstrates the potential of oil and dye desorption upon heating process.

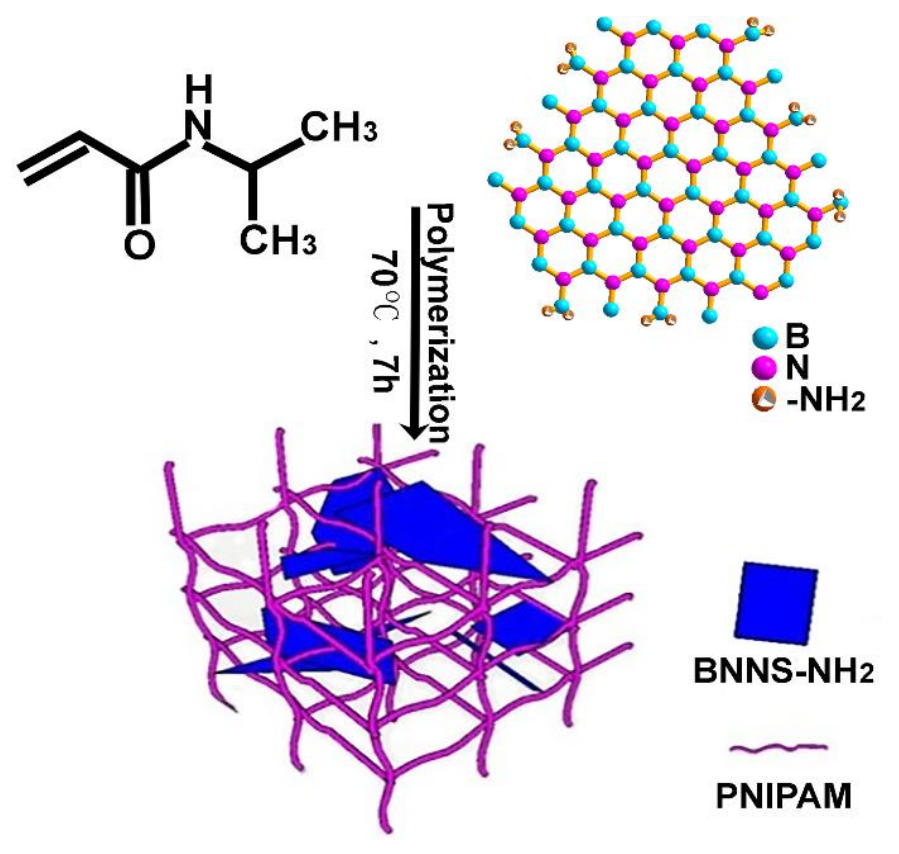

Scheme 1. Schematic illustration of the preparation of PNIPAM/BNNS-NH $\mathrm{N}_{2}$ hydrogels.

\section{Materials and Methods}

\subsection{Materials}

The $\mathrm{N}$-isopropylacrylamide (NIPAM), amino functionalized boron nitride nanosheet (BNNS-NH $\left.\mathrm{NH}_{2}\right)$ are used as reactants, the $N, N^{\prime}$-methylenebisacrylamide (BIS) and the azobisisobutyronitrile (AIBN) are used as crosslinking agent and initiator respectively. The NIPAM, BIS and AIBN were purchased from Sigma-Aldrich (Saint Louis, MO, USA). The BNNS-NH 2 was prepared by our previous work [14,29]. 


\subsection{Synthesis of the PNIPAM Hydrogels Incorporated with $B N N S-\mathrm{NH}_{2}$}

Different amounts of BNNS- $\mathrm{NH}_{2}$ were dispersed into alcohol and sonicated for $3 \mathrm{~h}$ and alcohol solution with the concentration of BNNS- $\mathrm{NH}_{2}$ equal to $0.02 \mathrm{mg} / \mathrm{mL}, 0.04 \mathrm{mg} / \mathrm{mL}, 0.06 \mathrm{mg} / \mathrm{mL}$, $0.10 \mathrm{mg} / \mathrm{mL}$ and $0.20 \mathrm{mg} / \mathrm{mL}$ were obtained respectively. Then, NIPAM $(0.6 \mathrm{~g})$, BIS (20 mg) and AIBN (22 mg) were added into alcohol solution of BNNS- $\mathrm{NH}_{2}(3 \mathrm{~mL})$ under stirring. The mixture was bubbled by $\mathrm{N}_{2}$ for $30 \mathrm{~min}$ and polymerized at $70{ }^{\circ} \mathrm{C}$ for $7 \mathrm{~h}$ to prepare PNIPAM/BNNS-NH $\mathrm{N}_{2}$ hydrogels, as displayed in Scheme 1. The as-prepared hydrogels were then washed with alcohol and water 3 times. Pure PNIPAM hydrogels were prepared just as the similar route but without adding the BNNS-NH $\mathrm{N}_{2}$.

\section{Results and Discussion}

The PNIPAM/BNNS-NH ${ }_{2}$ hydrogel was prepared with the concentration of BNNS- $\mathrm{NH}_{2}$ tuned from 0.02 to $0.20 \mathrm{mg} / \mathrm{mL}$. The hydrogels were characterized by Fourier transform infrared spectroscopy (FT-IR). As shown in Figure S1a,c, the weak but obvious band around $1930.3 \mathrm{~cm}^{-1}$ corresponds to the out of plane bending vibration of B-N-B, and the characteristic peaks of in-plane B-N stretching vibrations at $1314.8 \mathrm{~cm}^{-1}$ [14]. Figure S1b is FT-IR of pure PNIPAM hydrogel, the adsorption at $1556.3 \mathrm{~cm}^{-1}$ and $1625.7 \mathrm{~cm}^{-1}$ are assigned to stretching vibration of characteristic amide group and carbonyl moiety in $[-\mathrm{C}(\mathrm{O})-\mathrm{NH}-]$. The band at $2978.6 \mathrm{~cm}^{-1}$ is due to the asymmetric vibration of $\mathrm{C}-\mathrm{H}$ in $-\mathrm{CH}_{3}$. The FT-IR of PNIPAM/BNNS-NH $\mathrm{N}_{2}$ hydrogels was shown in Figure S1c, the characteristic peaks at $1314.8 \mathrm{~cm}^{-1}$ is correlated with in-plane B-N stretching vibrations. The band at the range of $861.5-950.3 \mathrm{~cm}^{-1}$ is correlated with out-of-plane bending mode of h-BN [25], which illustrates that the h-BN is not thoroughly exfoliated to the BNNS, or some BNNSs re-agglomerate in the polymer array to be the bulk BN.

To determine the mass fraction of polymer in PNIPAM/BNNS-NH ${ }_{2}$ hydrogel, thermos-gravimetric analysis (TGA) is tested. As shown in Figure $\mathrm{S} 2$, the $\mathrm{BNNS}-\mathrm{NH}_{2}$ is stable in air up to $800{ }^{\circ} \mathrm{C}$, any weight loss below that temperature is caused by the decomposition of amino groups [14]. The results of TGA illustrates that the composite hydrogel is chemical stably below $300{ }^{\circ} \mathrm{C}$ which is important in practical applications. In addition, for PNIPAM/BNNS- $\mathrm{NH}_{2}$ hydrogel prepared from $\mathrm{BNNS}-\mathrm{NH}_{2}$ solution with concentration of $0.06 \mathrm{mg} / \mathrm{mL}$, the weight loss of $7.7 \%$ is due to water in the hydrogel, and the residual weight loss of $83.7 \%$ is because of thermal degradation of PNIPAM.

The hydrogels with and without $\mathrm{BNNS}-\mathrm{NH}_{2}$ were lyophilized and observed by scanning electron microscopy (SEM). As shown in Figure 1a-c, the pure PNIPAM exhibits the typical porous morphology, while the PNIPAM/BNNS- $\mathrm{NH}_{2}$ demonstrates the distinct porous structure with lamellar. The SEM images also show that BNNS- $\mathrm{NH}_{2}$ is clearly inside the porous PNIPAM/BNNS- $\mathrm{NH}_{2}$ hydrogel (Figure 1c). LCST of PNIPAM/BNNS- $\mathrm{NH}_{2}$ hydrogel is around $34{ }^{\circ} \mathrm{C}$, as tested in Figure S3. Thermo-responsiveness of pure PNIPAM and PNIPAM/BNNS- $\mathrm{NH}_{2}$ hydrogels can be observed by poured the samples into hot water $\left(42{ }^{\circ} \mathrm{C}\right)$ at the same time. As shown in Figure $1 \mathrm{~d}-\mathrm{f}$, the PNIPAM/BNNS-NH ${ }_{2}$ hydrogel changes from transparent to turbid more quickly than that of PNIPAM hydrogel owing to respond to elevating of temperature more quickly in the presence of BNNS-NH ${ }_{2}$. This demonstrates that the heat transfer rate of PNIPAM/BNNS- $\mathrm{NH}_{2}$ hydrogel is effectively enhanced by BNNS- $\mathrm{NH}_{2}$. The composite hydrogel is more sensitive to the changing of temperatures, which is attributed to the superior thermal conductivity improved by introducing BNNS-NH ${ }_{2}[18]$. 


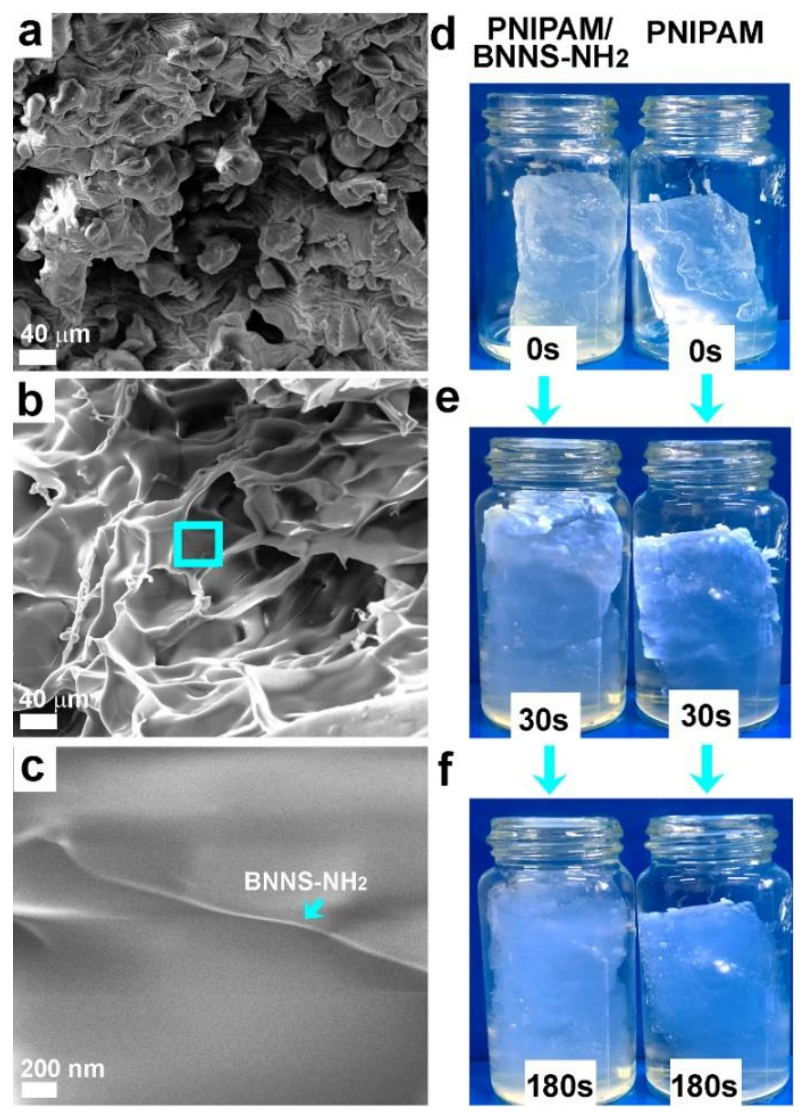

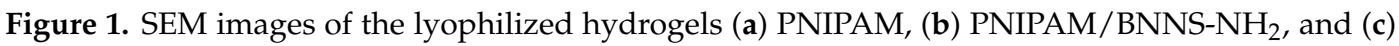
magnification at cross-section in (b). Photographs of the hydrogels placed in hot water $\left(42{ }^{\circ} \mathrm{C}\right)$ (the left one is PNIPAM/BNNS-NH ${ }_{2}$, the right one is pure PNIPAM): (d) before poured into hot water, (e) $30 \mathrm{~s}$ later and (f) $180 \mathrm{~s}$ later placed in hot water $\left(42^{\circ} \mathrm{C}\right)$.

The hydrophilicity/hydrophobicity of the hydrogel surfaces plays an important role in the oil and dye adsorption. The water contact angles of the material surfaces were used to evaluate the hydrophilicity/hydrophobicity of hydrogel in Figure 2. It is clear that the contact angles of PNIPAM/BNNS- $\mathrm{NH}_{2}$ hydrogels is $116^{\circ}$ at temperature above LCST (Figure 2a), which is more hydrophobic than pure PNIPAM $\left(107^{\circ}\right)$ as shown in Figure $2 \mathrm{~b}$. With the temperature decreasing to below LCST, the contact angle of the PNIPAM/BNNS- $\mathrm{NH}_{2}$ composite hydrogel decreases to $17^{\circ}$ (Figure 2c), which is more hydrophilic than pure PNIPAM $\left(21^{\circ}\right)$ as shown in Figure $2 \mathrm{~d}$.

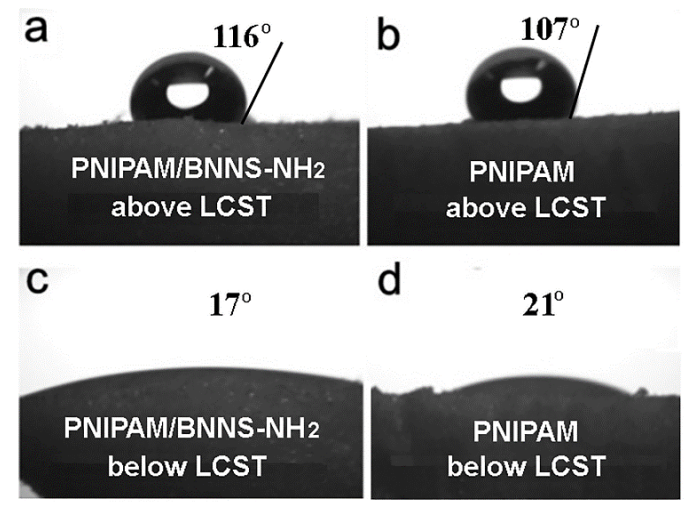

Figure 2. The pictures of contact angle: (a) PNIPAM/BNNS-NH ${ }_{2}$; (b) PNIPAM at above LCST; (c) PNIPAM/BNNS-NH 2 and (d) PNIPAM at below LCST. 
To demonstrate that the PNIPAM/BNNS- $\mathrm{NH}_{2}$ hydrogel possesses higher heat transfer efficiency than that of pristine PNIPAM, both the hydrogels were heated in the water bath at the same time, as shown in Figure 3. The PNIPAM/BNNS- $\mathrm{NH}_{2}$ hydrogel moves faster than that of pure PNIPAM hydrogel under heating (Figure $3 \mathrm{a}, \mathrm{b}$ ), indicating that $\mathrm{BNNS}^{-\mathrm{NH}_{2}}$ in the hydrogels enhances the thermal conductivity rate of the composite hydrogels. The PNIPAM/BNNS- $\mathrm{NH}_{2}$ hydrogel moves from bottom to top of cuvette under heating from room temperature to $40{ }^{\circ} \mathrm{C}$. The polymer chains are hydrophilic and extensive at room temperature, making hydrogel stay at the bottom of cuvette (Figure 3c). Conversely, the polymer chains are hydrophobic and shrinking when the aqueous solution is heated to $40{ }^{\circ} \mathrm{C}$ (above LCST) (Figure 3d,e). During the heating, polymeric chains at the bottom of hydrogel are shrinking (high temperature) and the polymeric chains on the top are extension (low temperature), which impels the hydrogel to move from higher temperature to lower temperature (from bottom to top). Herein, the extension and shrinking of polymeric chains in the hydrogels [7] cause movement of hydrogels under heating in water. The PNIPAM/BNNS- $\mathrm{NH}_{2}$ hydrogels exhibit potential applications as actuators or intelligent delivery carriers in the fields of petroleum, information technology, environmental and medical science.
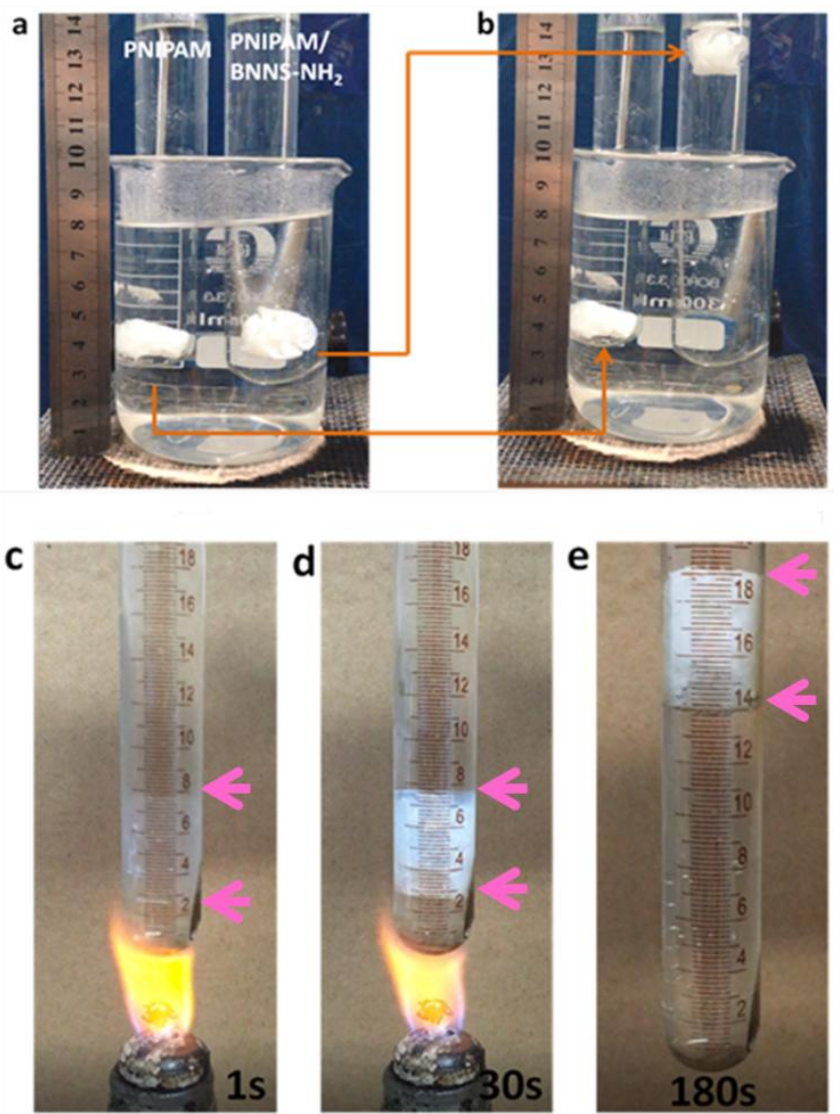

Figure 3. Digital photographs of hydrogels under heating: (a) at the beginning of heating, (b) heating for $10 \mathrm{~min}$ by a spirit lamp, PNIPAM/BNNS-NH 2 hydrogels were heated for (c) $1 \mathrm{~s}$, (d) $30 \mathrm{~s}$ and (e) $180 \mathrm{~s}$ from room temperature.

The hydrogel can be employed to absorb and release hydrophilic molecules under the control of temperature. As revealed in Figure S4, the hydrogels absorb hydrophilic dye (Rhodamine B) in aqueous solution at room temperature (below LCST). PNIPAM/BNNS- $\mathrm{NH}_{2}$ hydrogels absorbed Rhodamine B faster than that of PNIPAM hydrogels, which probably because of $\mathrm{BNNS}-\mathrm{NH}_{2}$ enhanced absorbing performance for dyes. In addition, the hydrogels which possess more BNNS- $\mathrm{NH}_{2}$ absorb dyes much faster, illustrating that $\mathrm{BNNS}-\mathrm{NH}_{2}$ improves spaces and enhances $\mathrm{H}$-bonds for absorbing 
more Rhodamine B [25]. The controlled releases of the absorbed Rhodamine B at high temperature (above LCST) are described in Figures 4 and S5. The absorbed dyes can be released at high temperature and PNIPAM/BNNS- $\mathrm{NH}_{2}$ hydrogels release dyes faster than pure PNIPAM hydrogels. PNIPAM/BNNS- $\mathrm{NH}_{2}$ hydrogels containing more $\mathrm{BNNS}-\mathrm{NH}_{2}$ exhibit faster releasing rate of absorbed dyes (Figure $4 \mathrm{a}-\mathrm{c}$ ). This may be attributed to the hydrogels with $\mathrm{BNNS}^{-\mathrm{NH}_{2}}$ which exhibit high thermal conductivity rate are more sensitive to heat. Importantly, the dyes in the composite hydrogels can be released completely after the hydrogels are put into the hot water for $10 \mathrm{~h}$ (Figure $4 \mathrm{~d}$,e), then the hydrogels can be recycled and reused many times, supporting a smart and recyclable equipment driven by temperature.

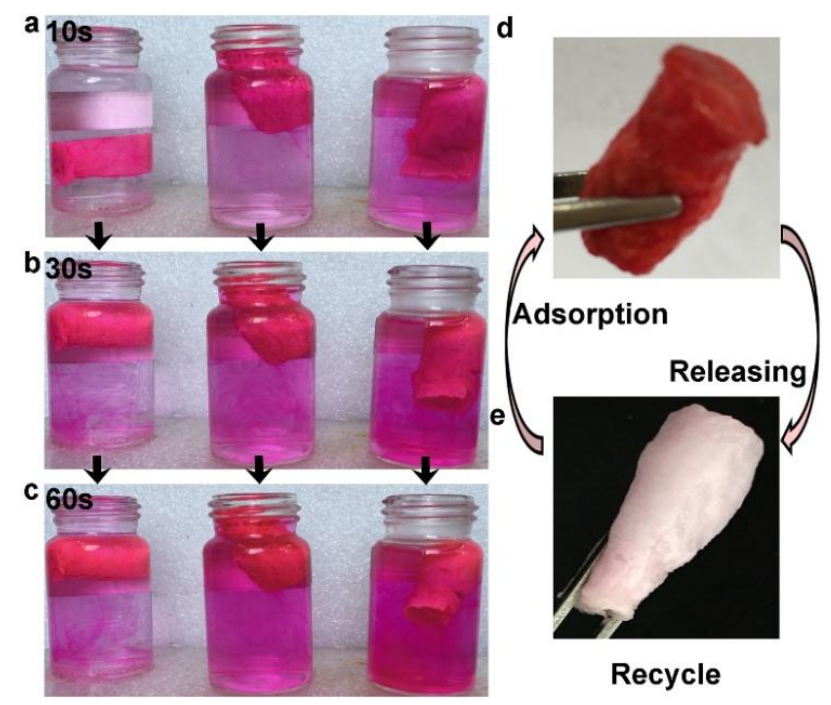

Figure 4. Photographs of dye release test, all samples were put in hot water for (a) $10 \mathrm{~s}$, (b) $30 \mathrm{~s}$ and (c) $60 \mathrm{~s}$. The bottles from left to right are pure PNIPAM and PNIPAM/BNNS-NH $\mathrm{N}_{2}$ prepared from BNNS- $\mathrm{NH}_{2}$ concentration of $0.02 \mathrm{mg} / \mathrm{mL}$ and $0.04 \mathrm{mg} / \mathrm{mL}$, respectively. Photographs of the PNIPAM/BNNS-NH $\mathrm{N}_{2}$ hydrogel: (d) before and (e) after releasing dye.

Significantly, the PNIPAM/BNNS- $\mathrm{NH}_{2}$ hydrogels with enhanced thermo-responsive property can also be used to absorb and release oleophilic molecules such as diesel by simply adjusting the temperatures. The absorption capacity for diesel is $3.7 \mathrm{~g} / \mathrm{g}$ at temperature above LCST, comparable to most polymeric oil-absorbents [30,31]. As shown in Figure 5 the absorbed diesel (dyed by blue colorant) can be effectively released when the temperature was lower than LCST. The hydrophilic-lipophilic properties of the fabricated hydrogels at above and below LCST lead to the design of smart sorbents from the thermo-responsive hydrogels.

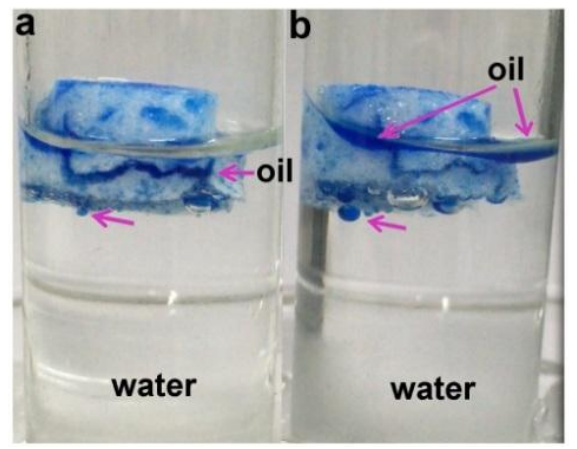

Figure 5. Photos of PNIPAM/BNNS-NH 2 hydrogels were put into the cold water for $5 \mathrm{~min}$ (a) and for $10 \min (\mathbf{b})$. 


\section{Conclusions}

In conclusion, bio-inspired sensitive thermo-responsive PNIPAM/BNNS-NH $\mathrm{N}_{2}$ hydrogels were prepared by an in situ polymerization route. These hydrogels are hydrophilic at a temperature below LCST, and hydrophobic at a temperature above LCST. The PNIPAM/BNNS-NH ${ }_{2}$ hydrogels which transfer heat much faster than pure PNIPAM hydrogels can move faster under heating. The thermal sensitive hydrogels can absorb and release Rhodamine B and oil under the control of heating and cooling. These features mean the composite hydrogels are promising actuators and can find potential applications in wide areas including drug delivery and water purification.

Supplementary Materials: The following are available online at http:/ /www.mdpi.com/1996-1944/11/7/1069/ s1, Figure S1: FT-IR spectra of (a) BNNS-NH ${ }_{2}$, (b) pure PNIPAM hydrogels and (c) PNIPAM/BNNS-NH $\mathrm{B}_{2}$ hydrogels. Figure S2: TGA curves of BNNS-NH $\mathrm{NH}_{2}$ (a) and PNIPAM/BNNS-NH $\mathrm{N}_{2}$ hydrogels with the concentration of BNNS-NH $\mathrm{NH}_{2} 0.06 \mathrm{mg} / \mathrm{mL}$ (b). Figure S3: LCST of the hydrogels (a) pristine PNIPAM; (b) PNIPAM with BNNS-NH $\mathrm{N}_{2}$ concentration of $0.02 \mathrm{mg} / \mathrm{mL}$; (c) PNIPAM with BNNS-NH $\mathrm{N}_{2}$ concentration of $0.04 \mathrm{mg} / \mathrm{mL}$; (d) the PNIPAM with BNNS-NH ${ }_{2}$ concentration of $0.06 \mathrm{mg} / \mathrm{mL}$; (e) the PNIPAM with BNNS- $\mathrm{NH}_{2}$ concentration of $0.10 \mathrm{mg} / \mathrm{mL}$; (f) the PNIPAM with BNNS- $\mathrm{NH}_{2}$ concentration of $0.20 \mathrm{mg} / \mathrm{mL}$. (The transmittance is tested at $700 \mathrm{~nm})$. Figure S4: Transmittance of dye solution after dye penetrant test (a) the dye solution which were put inside the hydrogels with different concentration $\mathrm{BNNS}-\mathrm{NH}_{2}$ for 2 days; (b) the original dye solution. (The transmittance is tested at $610 \mathrm{~nm}$ ). Figure S5: Transmittance of the dye solution after dye release test (a) the hydrogel without BNNS-NH${ }_{2}$ in hot water; (b) the hydrogel with the BNNS- $\mathrm{NH}_{2}$ concentration of $0.02 \mathrm{mg} / \mathrm{mL}$; (c) the hydrogel with the BNNS- $\mathrm{NH}_{2}$ concentration of $0.04 \mathrm{mg} / \mathrm{mL}$. (The transmittance is tested at $610 \mathrm{~nm}$ ).

Author Contributions: Y.W. and S.X. conceived and designed the experiments; S.X. and M.G. performed the experiments; Y.W., J.W. and D.L. analyzed the data; Y.W., W.L. and J.W. contributed reagents/materials/analysis tools; S.X., Y.W. and W.L. wrote the paper.

Funding: This research was funded by [Foundation of Sichuan Youth Science and Technology] grant number [2016JQ0036]; [Fok Ying Tung Education Foundation] grant number [No. 161103].

Acknowledgments: This work was financially supported by Foundation of Sichuan Youth Science and Technology (2016JQ0036), Fok Ying Tung Education Foundation (161103), Open Funds of State Key Laboratory of Petroleum Pollution Control (PPC2017008) and State Key Laboratory Oil and Gas Reservoir Geology and Exploitation (PLN1201, SWPU), Natural Science Foundation of Nanchong City (NC17SY4015) and Innovative Research Team of Southwest Petroleum University (2017CXTD01).

Conflicts of Interest: The authors declare no conflict of interest.

\section{References}

1. Chang, H.C.; Qin, J.L.; Xiao, P.S.; Yang, Y.; Zhang, T.F.; Ma, Y.F.; Huang, Y.; Chen, Y.S. Highly reversible and recyclable absorption under both hydrophobic and hydrophilic conditions using a reduced bulk graphene oxide material. Adv. Mater. 2016, 28, 3504-3509. [CrossRef] [PubMed]

2. Cai, P.Q.; Leow, W.R.; Wang, X.Y.; Wu, Y.L.; Chen, X.D. Programmable nano-bio interfaces for functional biointegrated devices. Adv. Mater. 2017, 29, 1605529. [CrossRef] [PubMed]

3. Jia, H.; Li, Z.; Wang, X.; Zheng, Z. Facile functionalization of a tetrahedron-like PEG macromonomer-based fluorescent hydrogel with high strength and its heavy metal ion detection. J. Mater. Chem. A 2015, 3, 1158-1663. [CrossRef]

4. White, E.M.; Yatvin, J.; Grubbs, J.B.; Bilbrey, J.A.; Locklin, J. Advances in smart materials: Stimuli-responsive hydrogel thin films. J. Polym. Sci. Part B Polym. Phys. 2013, 5, 1084-1099. [CrossRef]

5. Kang, D.H.; King, S.M.; Lee, B.; Yoon, H.; Suh, K.Y. Stimuli-responsive hydrogel patterns for smart microfluidics and microarrays. Analyst 2013, 138, 6230-6242. [CrossRef] [PubMed]

6. Zhang, Z.X.; Liu, K.L.; Li, J. A Thermoresponsive hydrogel formed from a star-star supramolecular architecture. Angew. Chem. Int. Ed. 2013, 52, 6180-6184. [CrossRef] [PubMed]

7. Yu, W.N.; Liu, S.X.; Wang, H.M.; Tian, R.J. Synthesis and micellization of P(NIPAM-co-HMAM)-bPEO- $b$-P(NIPAM-co-HMAM) triblock copolymers. Polym. Res. 2012, 19, 9989. [CrossRef]

8. Stetsyshyn, Y.; Fornal, K.; Raczkowska, J.; Zemla, J.; Kostruba, A.; Ohar, H.; Ohar, M.; Donchak, V.; Harhay, K.; Awsiuk, K.; et al. Temperature and $\mathrm{pH}$ dual-responsive POEGMA-based coatings for protein adsorption. J. Colloid Interface Sci. 2013, 411, 247-256. [CrossRef] [PubMed] 
9. Gong, Z.L.; Tang, D.Y.; Guo, Y.D. The fabrication and self-flocculation effect of hybrid $\mathrm{TiO}_{2}$ nanoparticles grafted with poly( $\mathrm{N}$-isopropylacrylamide) at ambient temperature via surface-initiated atom transfer radical polymerization. J. Mater. Chem. 2012, 22, 16872-16879. [CrossRef]

10. Huang, C.J.; Chang, F.C. Polypeptide diblock copolymers: Syntheses and properties of poly(N-isopropylacrylamide)-b-polylysine. Macromolecules 2008, 41, 7041-7052. [CrossRef]

11. Lu, X.J.; Zhang, L.F.; Meng, L.Z.; Liu, Y.H. Synthesis of poly(N-isopropylacrylamide) by ATRP using a fluorescein-based initiator. Polym. Bull. 2007, 59, 195-206. [CrossRef]

12. Lutz, J.F.; Akdemir, O.; Hoth, A. Point by point comparison of two thermosensitive polymers exhibiting a similar LCST: Is the age of poly(NIPAM) over? J. Am. Chem. Soc. 2006, 128, 13046-13047. [CrossRef] [PubMed]

13. Wei, H.; Wu, D.Q.; Li, Q.; Chang, C.; Zhou, J.P.; Zhang, X.Z.; Zhuo, R.X. Preparation of shell cross-linked thermoresponsive micelles as well as hollow spheres based on P(NIPAAm-co-HMAAm-co-MPMA)- $b$-PCL. J. Phys. Chem. C 2008, 112, 15329-15334. [CrossRef]

14. Lei, W.W.; Mochalin, V.N.; Liu, D.; Qin, S.; Gogotsi, Y.; Chen, Y. Boron nitride colloidal solutions, ultralight aerogels and freestanding membranes through one-step exfoliation and functionalization. Nat. Commun. 2015, 6, 8849. [CrossRef] [PubMed]

15. Marsh, K.L.; Souliman, M.; Kaner, R.B. Co-solvent exfoliation and suspension of hexagonal boron nitride. Chem. Commun. 2015, 51, 187-190. [CrossRef] [PubMed]

16. Weng, Q.H.; Wang, B.J.; Wang, X.B.; Hanagata, N.; Li, X.; Liu, D.; Wang, X.; Jiang, X.F.; Bando, Y.; Golberg, D. Highly water-soluble, porous, and biocompatible boron nitrides for anticancer drug delivery. ACS Nano 2014, 8, 6123-6130. [CrossRef] [PubMed]

17. Lei, W.W.; Zhang, H.; Wu, Y.; Zhang, B.; Liu, D.; Qin, S.; Liu, Z.W.; Liu, L.M.; Ma, Y.M.; Chen, Y. Oxygen-doped boron nitride nanosheets with excellent performance in hydrogen storage. Nano Energy 2014, 6, 219-224. [CrossRef]

18. Chen, Z.G.; Zhou, J. Field emitters: Ultrathin BN nanosheets protruded from BN fibers. J. Mater. Chem. 2011, 21, 1191-1195. [CrossRef]

19. Cong, H.P.; Qiu, J.H.; Yu, S.H. Thermoresponsive poly(N-isopropylacrylamide)/Graphene/Au nanocomposite hydrogel for water treatment by a laser-assisted approach. Small 2015, 11, 1165-1170. [CrossRef] [PubMed]

20. Pan, Y.Z.; Bao, H.Q.; Sahoo, N.G.; Wu, T.F.; Li, L. Water-soluble poly(N-isopropylacrylamide) and ash; graphene sheets synthesized via click chemistry for drug delivery. Adv. Funct. Mater. 2011, 21, 2754-2763. [CrossRef]

21. Yang, K.; Feng, L.Z.; Shi, X.Z.; Liu, Z. Nano-graphene in biomedicine: Theranostic applications. Chem. Soc. Rev. 2013, 42, 530-547. [CrossRef] [PubMed]

22. Zhang, J.Y.; Du, P.; Xu, D.Y.; Li, Y.; Peng, W.C.; Zhang, G.L.; Zhang, F.B.; Fan, X.B. Near-infrared responsive $\mathrm{MoS}_{2} /$ poly(N-isopropylacrylamide) hydrogels for remote light-controlled microvalves. Ind. Eng. Chem. Res. 2016, 55, 4526-4531. [CrossRef]

23. Cui, Z.H.; Martinez, A.P.; Adamson, D.H. PMMA functionalized boron nitride sheets as nanofillers. Nanoscale 2015, 7, 10193-10197. [CrossRef] [PubMed]

24. Lei, W.W.; Portehault, D.; Liu, D.; Qin, S.; Chen, Y. Porous boron nitride nanosheets for effective water cleaning. Nat. Commun. 2013, 4, 1777. [CrossRef] [PubMed]

25. Feng, X.; Sina, N.; Gilberto, C.; Majharul, H.K.; Tomas, K.; Lei, J.; Liu, H.K.; Li, H.J.; Huang, Z.G. Edge-hydroxylated boron nitride nanosheets as an effective additive to improve the thermal response of hydrogels. Adv. Mater. 2015, 27, 7196-7203.

26. Wu, X.; Liu, H.; Tang, Z.H.; Guo, B.C. Scalable fabrication of thermally conductive elastomer/boron nitride nanosheets composites by slurry compounding. Compos. Sci. Technol. 2016, 123, 179-186. [CrossRef]

27. Wang, X.B.; Zhi, C.Y.; Weng, Q.H.; Bando, Y.; Golberg, D. Boron nitride nanosheets: Novel syntheses and applications in polymeric composites. J. Phys. Conf. Ser. 2013, 471, 012003. [CrossRef]

28. Liu, D.; Lei, W.W.; Klika, K.D.; Kong, L.X.; Chen, Y. Multifunctional polymer/porous boron nitride nanosheet membranes for superior trapping emulsified oils and organic molecules. Adv. Mater. Interfaces 2015, 2, 1500228. [CrossRef] 
29. Lee, D.J.; Lee, B.; Park, K.H.; Ryu, H.J.; Jeon, S.; Hong, S.H. Scalable exfoliation process for highly soluble boron nitride nanoplatelets by hydroxide-assisted ball milling. Nano Lett. 2015, 15, 1238-1244. [CrossRef] [PubMed]

30. Wu, Y.P.; Xue, S.S.; Yang, H.; Zhang, H.Y.; Zhang, T.; Gou, S.H. Polymerization-induced phase separation for the fabrication of magnetic sponges for oil spill reclamation. Chem. Eng. J. 2017, 328, 639-644. [CrossRef]

31. Mo, J.; Xu, N.; Xiao, C.; Cheng, B.; Han, X. Polymethacrylate-based fiber containing an interpenetrating polymer network and its use for oil absorption. Fibers Polym. 2015, 16, 8-16. [CrossRef]

(C) 2018 by the authors. Licensee MDPI, Basel, Switzerland. This article is an open access article distributed under the terms and conditions of the Creative Commons Attribution (CC BY) license (http:/ / creativecommons.org/licenses/by/4.0/). 